\title{
Educa Direito: Um Jogo Sério para o Ensino de Direito do Trabalho
}

\author{
Title: Educa Direito: A Serious Game for the Teaching of Labor Law
}

Vania Cristina Bordin Freitas

Universidade Federal do Rio Grande - FURG

2.vania@gmail.com

\author{
Diana Adamatti \\ Universidade Federal do Rio Grande - FURG \\ dianaada@gmail.com
}

\begin{abstract}
Resumo $O$ processo de ensino-aprendizagem possibilita aos estudantes desenvolver conhecimentos, habilidades e atitudes, que são construidos e armazenados consigo ao longo da vida. Nesse sentido, o objetivo deste trabalho é desenvolver um jogo sério web para o ensino da disciplina de direito do trabalho e previdenciário do curso Técnico em Administração, com o intuito de auxiliar na aprendizagem dos estudantes. $O$ desenvolvimento do estudo ocorre em etapas, nas quais, na primeira etapa são delimitados o problema e os objetivos abordados, na segunda etapa as ferramentas utilizadas para o desenvolvimento do jogo, na terceira etapa foram elaboradas e inseridas as questões referentes aos conteúdos trabalhados em sala de aula durante o semestre, na quarta etapa o desenvolvimento do jogo e na quinta etapa foram aplicados os questionários com os estudantes. Os resultados obtidos com as aplicações dos questionários foram satisfatórios, pois verificou-se o interesse e o conhecimento dos estudantes em jogos eletrônicos e com o jogo Educa Direito e quanto os jogos sérios podem contribuir com o processo de ensino-aprendizagem.
\end{abstract}

Palavras-Chave: ensino-aprendizagem, jogos educativos, direito do trabalho

\begin{abstract}
The teaching-learning process makes possible the students to develop knowledge, abilities, attitudes, that are built and stored with itself along the life. In that sense, the objective of this work is to develop a game serious web for the teaching of the discipline of labor law and social security of the Technical course in Administration, with the intention of aiding in the students' learning. The development of the study takes place in step, in which the first stage is defined the problem and addressed goals, in the second step of the tools used for the development of the game, in the third step were prepared and inserted the issues related to room in contents worked class during the semester, in the fourth step the development of the game and the fifth step the questionnaires were applied with the students. The results obtained with the applications of the questionnaires were satisfactory, because we could verified the interest and knowledge of the students in electronic games and with the Educa Direito game, proving that serious games can contribute with the teaching-learning process.
\end{abstract}

Keywords: teaching-learning, educational games, labor law 


\section{Introdução}

O processo de ensino-aprendizagem proporciona aos estudantes conhecimentos, habilidades, valores, técnicas e aperfeiçoamentos que são desenvolvidos ao longo da vida, a partir da convivência com outras pessoas e ambientes. No momento que esses conhecimentos são aprimorados, simulados e testados, devem ser armazenados e mantidos consigo mesmo, pois são fundamentais para formação da opinião de cada indivíduo [1], [2].

$\mathrm{O}$ ensino do direito do trabalho e previdenciário para o curso técnico em administração é um processo um tanto cansativo, pois visa compreender normas, institutos e regras do direito do trabalho aos estudantes de outra área, conhecimento que é primordial para sua formação.

O direito do trabalho tem por finalidade buscar melhores condições de serviço para o trabalhador, enquanto cidadão no seu encargo, pois é composto por princípios, institutos e regras que visam o bem-estar do empregado [3]. Com isso, o professor deve buscar alternativas que motivem os estudantes, desmitificando a ideia de que o direito do trabalho é composto por normas, institutos e regras um tanto complexas.

A inserção de jogos em sala de aula, para auxiliar no processo de ensino-aprendizagem, pode ser um bom recurso didático para induzir o conhecimento, uma vez que jogos educativos ou sérios têm a finalidade de instruir e educar os jogadores sobre o tema ou assunto proposto pelo professor, o qual ele deseja ensinar [4].

Os jogos educativos têm em suas composições propostas, estímulos que levam os jogadores a compreender regras, imaginar alternativas de vencer o jogo, até imaginar novas possibilidades de interação com o ambiente proposto, aumentando assim seu processo de aprendizagem [5].

Para o desenvolvimento de jogos educativos computacionais, são utilizados métodos intuitivos que proporcionem novas possibilidades de ensino aos estudantes, construindo seus estímulos para novos processos de aprendizagem, o que facilita o ensinamento do conteúdo pelo professor, pois são maneiras mais prazerosas de aprender e ensinar os conteúdos vistos em aula [5].

Portanto, o objetivo deste estudo é desenvolver um jogo sério web para o ensino da disciplina de direito do trabalho e Previdenciário do curso Técnico em Administração do Colégio Politécnico da UFSM, com o intuito de auxiliar no processo de ensino-aprendizagem dos estudantes.

\section{Jogos sérios}

Com o avanço tecnológico, novos métodos de ensino estão sendo propostos, para auxiliar no processo de ensino-aprendizagem. Com isso, a educação tem-se equiparado com sistemas e ferramentas que vem se expandido muito no processo educativo [4]. A educação alicerçada de jogos eletrônicos está se expandido por aproximar artifícios lúdicos a conteúdos trabalhados em sala de aula, provendo melhores estratégias de aprendizagem frente ao ensino [4]. Estes jogos com fins específicos, que buscam estimular o raciocínio, a compreensão, o conhecimento, a discussão, novos métodos, são conhecidos como serious games ou jogos sérios [4].

De acordo com [6], a utilização de jogos sérios, tem o propósito de diversificar a limitação metodológica no ensino superior, oportunizando aos estudantes uma aula mais atrativa e dinâmica, pois a lição tradicional leva a dispersão e a falta de atenção. Nos cursos jurídicos são importantes adaptar metodologias educacionais juntamente com as tecnologias a fim de proporcionar: revisões de procedimentos e métodos de ensino; utilização de novas ferramentas de ensino; valorização da interdisciplinaridade da aprendizagem [7].

Desta forma, o autor [8], busca mostrar que os jogos sérios vinculam a seriedade do raciocínio e a solução do problema de maneira experimental com a motivação do jogo, pois, sua composição pode abranger dramas ou problemas de um assunto no qual o estudante deve adotar papéis realísticos para resolver determinada situação.

Os jogos sérios, segundo [9], são elucidados como uma competição, na qual o competidor deve seguir regras para avançar as etapas preestabelecidas pelo jogo. Esses jogos pretendem envolver os jogadores com a situação apresentada, buscando métodos diferenciados de ensino, entretenimento, estratégia e técnicas motivacionais de aprendizagem.

Já para [10], jogos sérios tem como intuito a integração dos aspectos lúdicos ao ensino, à aprendizagem, à comunicação e à informação, de uma maneira diferenciada de ensinar o que está sendo proposto pelo professor, junto ao estudante, buscando seu envolvimento no processo educacional.

Os jogos sérios estão inclusos em um grupo de jogos nos quais seus conteúdos e recursos têm um fim específico, fazendo com que o jogador utilize métodos para resolver problemas, conhecer novas técnicas e praticar atividades que buscam simular situações vividas no dia-adia [4], [9].

Para [11], os jogos são desenvolvidos e buscam expressar ao jogador, métodos diferenciados de aprendizagem como, e.g., ação em vez de explicação, motivação e 
satisfação, instigar e impulsionar habilidades e estilos cognitivos, estimulando novos meios de pensar e agir e permitindo interatividade e tomada de decisão.

\section{Direito do Trabalho}

Conforme os preceptores, o direito do trabalho apresenta diversos conceitos [12], visando o trabalho digno ao cidadão, oposto ao que acontecia antigamente [13]. Segundo [14], o direito do trabalho é formado por regras, princípios e instituições voltados para as condições do trabalho e para o trabalhador, propondo melhores oportunidades de emprego.

Para [15] e [16], o direito do trabalho é formado por um montante de regras e princípios jurídicos que conduzem laços, a partir da prestação de serviço entre os envolvidos, trabalhadores e empregadores, para então, regulamentar os preceitos de trabalho.

Segundo [17], o direito do trabalho visa a esfera da ciência do direito, a qual tem como finalidades normas que regem as relações do trabalho realizado pelo empregado e empregador.

Na opinião de [18], o direito do trabalho é o campo do direito que regulamenta o relacionamento entre o empregado e o empregador, tendo como aspecto o trabalho subordinado, proporcionando melhores condições sociais para o trabalhador, conforme as normas e instituições que visam a disposição do trabalho e de sua elaboração frente a empresa.

O direito do trabalho tem por objetivo regulamentar a relação do empregado, conforme suas condições, independente, temporário, doméstico e eventual, visando obter uma medida de proteção de acordo com as normas e regras que regem essa função [12]. Tem como interesse o tipo de atividade realizada pelo cidadão ou a favor dele, no qual há envolvimento entre as pessoas, patrão e empregado, que vão se beneficiar com os lucros do trabalho realizado [13].

Nesse sentido, o direito do trabalho busca aprimorar as condições trabalhistas para os empregados, garantindo melhores condições sociais e de trabalho, oferecendo uma vida merecedora aos funcionários e empregadores [3].

\section{Trabalhos Correlatos}

Com o intuito de apresentar a relevância desta proposta, alguns trabalhos a seguir corroboram com a presente pesquisa.
O trabalho de [19], propõem uma ferramenta para criação de jogos de perguntas e respostas a partir de modelos em Redes de Petri Coloridas (RPC), no qual é possível modelar RPG, o designer pode criar jogos de perguntas e respostas. Localidades, caminhos e regras são definidas para o jogo a partir das características do RPG. Essa ferramenta permite que testes e simulações sejam realizados antes da implementação final do software. No quiz não é necessária programação, com isso usuário com pouco conhecimento em programação pode realizar seu jogo. Portanto, é possível criar jogos com baixo custo e de forma fácil e produtiva.

Já [20], apresenta um jogo digital chamado "Cidades dos Bits", proposto para o ensino de fundamentos da Ciência da Computação no Nível Médio. O jogo busca apresentar formas de aprendizagem significativas, buscando investigar o conhecimento do estudante sobre fundamentos de computação e suas habilidades. A versão atual do jogo tem por desafio fazer com que o usuário pratique jogos dos anos 80. O Jogo deve ser aplicado aos estudantes da rede pública do ensino médio para verificar sua aceitação.

A pesquisa apresentada em [21] descreve um jogo de mercado de trabalho, denominado Job Jungle. Nesse jogo, os participantes atuam como trabalhadores, empregadores e professores. Os trabalhadores têm como objetivo ganhar o maior lucro total e os empregadores de gerar o maior lucro total. O jogo é praticado quando: discute-se a procura de trabalho e fornecimento com os estudantes; distribuem-se as peças do jogo; preço de mercado e assistência pública; repete-se as metas de trabalhadores e empregadores; explica-se o processo de contratação; explica-se como os trabalhadores adquiram habilidades; joga-se a primeira rodada; e termina-se o jogo.

Os trabalhos expostos apresentam características semelhantes ao estudo desenvolvido, porém, podem apresentar algumas distinções, como: os autores [19] tomaram como base o modelo em Redes de Petri Coloridas para desenvolver o quiz. Já, no trabalho de [20] foi proposto um jogo para o ensino de fundamentos da Ciência da Computação no Nível Médio. Na pesquisa de [21] os participantes assumiram papéis de trabalhadores, empregadores e professores, aplicando seus conhecimentos no jogo a fim de obter lucros. Contudo, na proposta deste trabalho, desenvolveu-se um jogo em forma de quiz para desenvolver habilidades no ensino teórico de direito do trabalho na plataforma Visual Studio. 


\section{Modelagem e Desenvolvimento do Jogo}

Este trabalho tem como proposta abordar o desenvolvimento de um jogo sério para o ensino da disciplina de direito do trabalho e previdenciário do curso Técnico em Administração do Colégio Politécnico da UFSM, com o intuito de auxiliar no processo de ensino-aprendizagem.

A natureza desta pesquisa é considerada aplicada, conforme [22], pois objetiva-se na formação de conhecimento do indivíduo de forma prática, voltado para a resolução de problemas característicos. Em relação à abordagem do problema, a pesquisa ocorre de forma experimental - pelo fato da análise ser feita para construir um método de aprendizagem diferenciado daquele de sala de aula, que busca trabalhar os conteúdos aprendidos durante o semestre e proporcionar novos métodos de aprendizagem através da aplicação do jogo - e qualitativa pelo fato de apresentar uma nova técnica de ensino, que procura comparar métodos já existentes, no qual disponibiliza aos estudantes novas oportunidades de aprendizagem [23].

\subsection{Etapas da Pesquisa}

Esta pesquisa está organizada por etapas, a fim de facilitar cada processo realizado.

\subsubsection{Delineamento da Pesquisa}

$\mathrm{Na}$ primeira etapa da pesquisa são delimitados o problema e os objetivos abordados no decorrer do estudo, além de um mapeamento sistemático sobre o tema e uma revisão literária dos assuntos levantados.

Para o seguinte mapeamento sistemático foi realizada uma busca manual e automática na base Google Scholar entre o período de 2010 a 2015, utilizando a string de busca: "Jogos educacionais", "educational games", "jogos educativos", "educational games", "jogos de aprendizagem", "learning games", "jogos sérios", "serious games", "quiz”, "direito do trabalho", "labor law". Os resultados encontrados foram em média 10.000 estudos, porém, nenhum relacionado a jogos educacionais ou jogos sérios e direito do trabalho especificamente.

\subsubsection{Definição das ferramentas}

Após definir a proposta, foram selecionadas as ferramentas que seriam utilizadas para o desenvolvimento do jogo sério.

Para o desenvolvimento do jogo optou-se pela utilização da linguagem de programação C\#, por ser uma linguagem clara, simples, flexível e fácil e funcionar na plataforma Visual Studio [24]. Para o armazenamento das informações, foi escolhido o banco de dados MySql, por ser open source. Porém, a plataforma Visual Studio 2013 não está integrada a este banco de dados. Então, foi necessário instalar o MySql Connect Net, que permite a utilização de ambas ferramentas.

\subsubsection{Indexamento dos conteúdos educacio- nais no Jogo}

Durante a terceira etapa foram elaboradas e inseridas as questões referentes aos conteúdos trabalhados em sala de aula durante o semestre. Para a criação das questões do jogo, foi contatado o professor da disciplina para auxiliar com o conteúdo e sua produção. Na Figura 1 é possível observar algumas perguntas do jogo.

Qual lei que rege as relaçôes de trabalho?
a) Código Tributário Nacional
b) Código Penal
c) Biblia Sagrada
d) Consolidação das Leis de Trabalho (CLT)
São direitos dos trabalhadores, exceto:
a) Décimo terceiro salário
b) Salário mínimo
c) Férias de 35 dias
d) Aposentadoria
São elementos essenciais da relação de emprego, exceto:
a) Pessoalidade
b) Onerosidade
c) Não eventualidade
d) Insubordinação
Qual a Alternativa Incorreta?
a) Empregado é toda pessoa física que prestar serviço de natureza não eventual a
empregador, sob dependéncia deste e mediante salário.
b) Oempregado doméstico não tem direito a licença maternidade e paternidade.
c) E um direito previsto na Constituição Federal a remuneração do trabalho noturno superior
ao do diurno.
d) Nenhuma das Alternativas.
t..... é a contraprestação mínima devida e paga diretamente pelo empregador a todo
trabalhador, inclusive ao trabalhador rural, sem distinção de sexo, por dia normal de serviço,
e capaz de satisfazer, em determinada época e regiấo do País, as suas necessidades normais
de alimentação, habitação, vestuário, higiene e transporte. A palavra que completa
corretamente a frase é:
a) Férias
b) Décimo terceiro salário
c) Salário mínimo
d) Um terço de férias

Figura 1: Questões do Jogo Educa Direito

\subsubsection{Desenvolvimento do Jogo Sério - Edu- ca Direito}

$\mathrm{Na}$ quarta etapa foi desenvolvido o jogo sério, chamado de "Educa Direito", por ser um jogo voltado para o ensino da disciplina da área de direito. Este jogo foi criado com o propósito de auxiliar no processo de ensinoaprendizagem dos estudantes do curso técnico em Administração.

O jogo foi desenvolvido para web, através da linguagem de programação C\#, JavaScript, jQuery e banco de dados MySql.jQuery é uma biblioteca de JavaScript, com muitos recursos, que auxilia no desenvolvimento e criação de programas [25].

No diagrama Entidade-Relacionamento apresentado na Figura 2, é possível observar como o banco de dados foi elaborado para o desenvolvimento do jogo. 


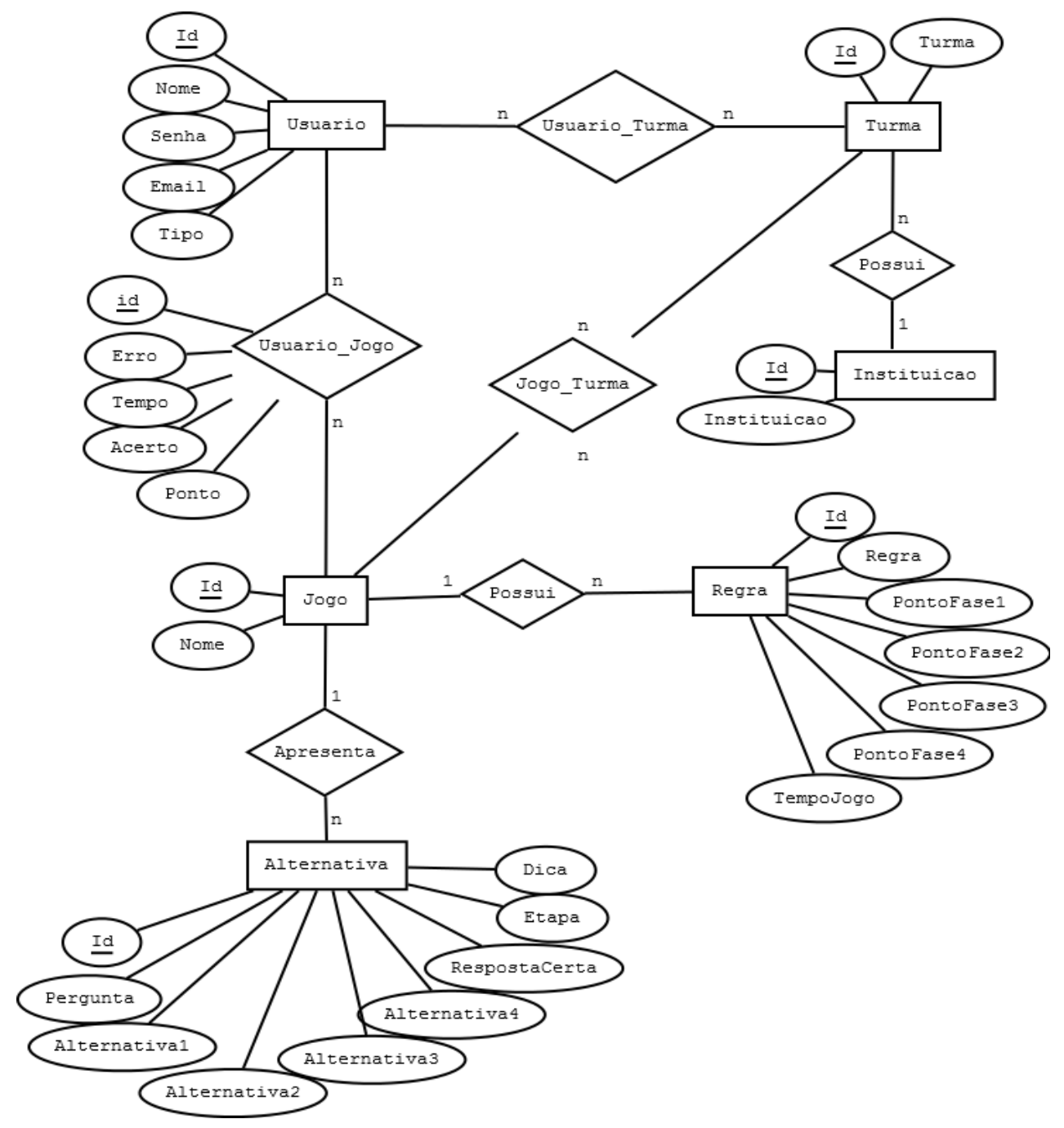

Figura 2: Diagrama Entidade-Relacionamento do Jogo Educa Direito

A Figura 2 é composta pelas entidades que representam as tabelas do banco de dados, juntamente com seus atributos e relacionamentos.

Na tabela Usuário são cadastrados os participantes do jogo, que devem informar: Nome, Senha, Email e o Tipo no qual seleciona-se a opção estudante ou professor, pois assim, habilita opções diferentes na página do jogo.

A tabela Jogo registra o Nome do jogo. Na tabela Regra, são cadastradas informações necessárias para a Regra do jogo, os pontos por fase (foram definidas 4 fases) que são: PontoFase1, PontoFase2, PontoFase3, PontoFase4; e um tempo total para o jogo, TempoJogo.

$\mathrm{Na}$ tabela Instituição é informado um nome para o campo Instituição e para tabela Turma, o nome da Turma que vai utilizar o jogo. $\mathrm{Na}$ tabela Alternativa são cadastrados os dados: da Pergunta do jogo, quatro alternativas,
Alternativa1, Alternativa2, Alternativa3, Alternativa4, além de informar a RespostaCerta, a Etapa que esta pergunta pertence e uma Dica que possa auxiliar o estudante em caso de erro.

Na nova tabela que se formou (n-n) Usuario Jogo são armazenados o Id da tabela Usuario e o Id da tabela Jogo, os quais são chaves estrangeiras desta tabela, juntamente com os atributos: Pontos, Acerto, Erro, Tempo que o usuário obteve ao jogar. As outras tabelas (n-n) que foram criadas, foram Usuario_Turma que tem como chaves estrangeiras o Id da tabela Usuario e o Id da tabela Turma e Jogo Turma que armazena o Id da tabela Jogo e o Id da tabela Turma, como chaves estrangeiras. As tabelas Usuario, Turma, Instituicao, Jogo, Alternativa, Regra e Usuario_Jogo tem o campo Id como chave primária e são auto incremento. 
O professor será o responsável pela manutenção do jogo, sendo que ele pode criar jogos com outros temas, para outras disciplinas, além da disciplina de direito do trabalho e previdenciário que é o foco deste trabalho.

Para a interface do jogo foi feito um estudo em jogos em formato de quiz, analisando-se os processos de jogabilidade, para então, definir regras, etapas, tempo, pontuação, recursos sonoros para respostas corretas, erradas, entre outras. Conforme a Figura 3 é possível visualizar as funcionalidades do jogo. O Diagrama de Caso de Uso do Educa Direito foi a opção para apresentar o GDD (Game Design Document) do jogo, pois apresenta de forma sucinta e de fácil entendimento as funcionalidades do jogo, bem como a inter-relação entre seus atores (Estudante e Professor).

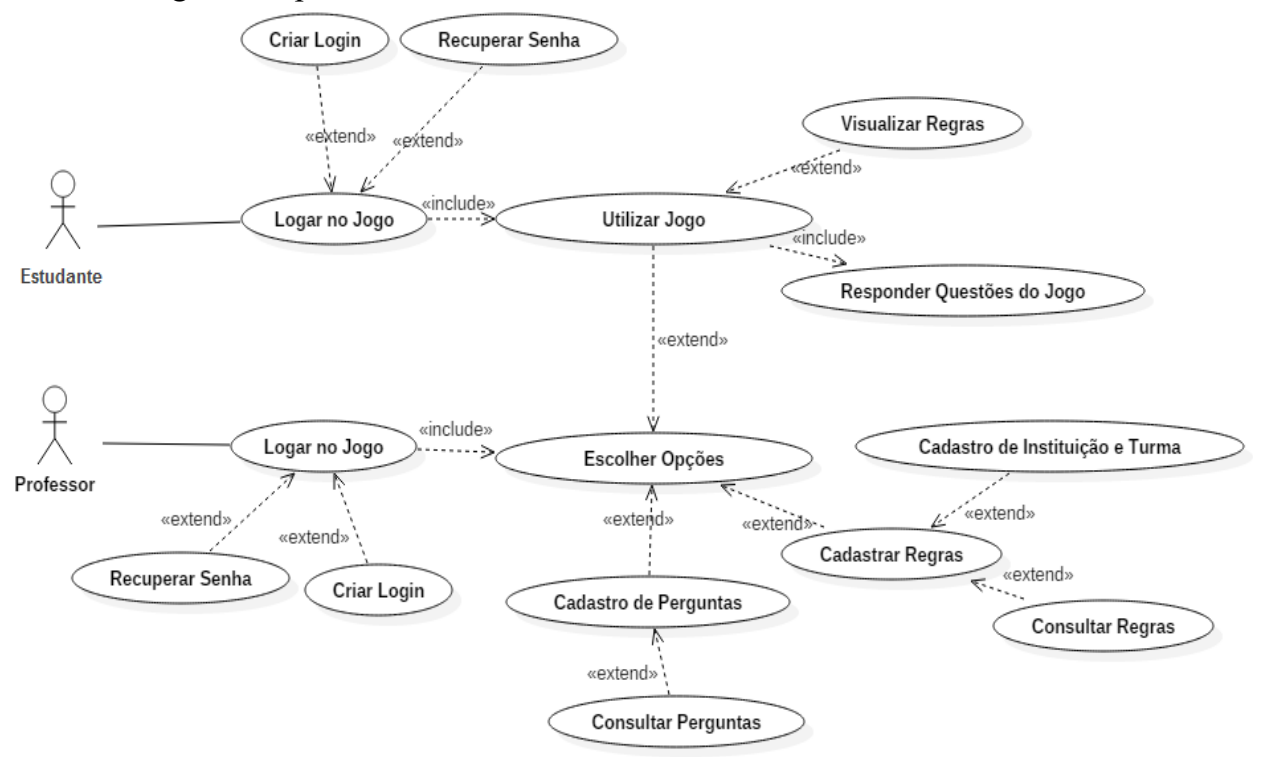

Figura 3: Diagrama de Caso de Uso do Jogo Educa Direito

De acordo com a Figura 3, o ator (estudante ou professor), ao acessar a página inicial, deve entrar no sistema de jogos. Caso não possua login, deve criá-lo e se esqueceu sua senha, deve recuperá-la, como nas Figuras 4, 5 e 6.

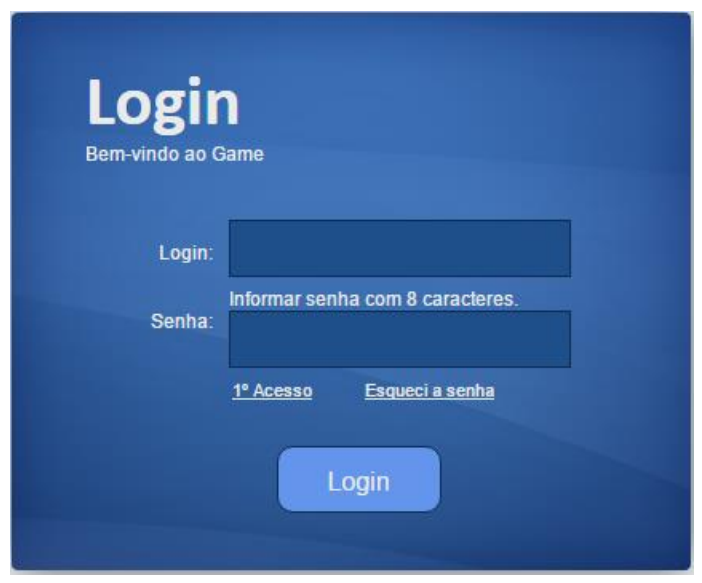

Figura 4: Tela Login

$\mathrm{Na}$ Figura 4, o usuário deve informar login e senha criado no cadastramento de login para posteriormente escolher o jogo Educa Direito. Para manter a segurança dos dados do usuário, foi utilizado o algoritmo Tripe DES para criptografia da senha do usuário. O Algoritmo Tripe DES considerado seguro, e faz a criptografia da informação com três chaves [26].

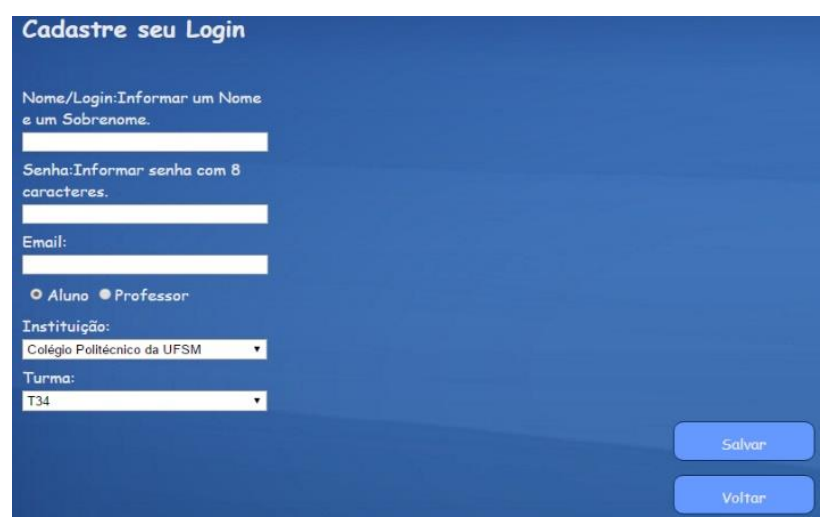

Figura 5: Tela Cadastro de Login

$\mathrm{Na}$ Figura 5, o usuário deve criar seu login para o jogo, informando nome, senha, e-mail, selecionar estudante ou professor, escolher instituição e turma e salvar. Depois, voltar para a tela de login. 


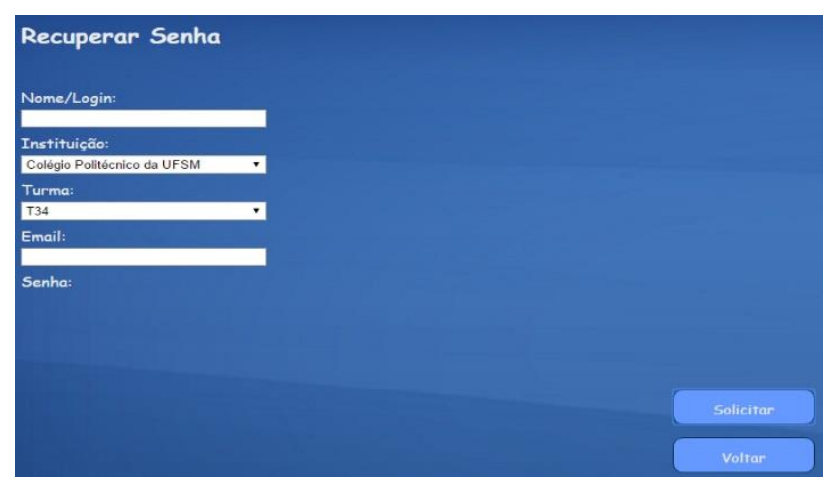

Figura 6: Tela Recuperar Login

Na Figura 6, o usuário pode recuperar sua senha em caso de esquecimento, informando nome, selecionando instituição, turma e informando e-mail e clicando em solicitar e será exibido a senha do usuário, após deve clicar em voltar e irá para tela de login.

O jogo envolve dois atores, o estudante e o professor, conforme descrição a seguir:

Se o ator for estudante:

- Ao se logar, deve utilizar o jogo, selecionando o jogo "Educa Direito" e com isso tendo a possibilidade de visualizar suas regras, jogar ou voltar, como na Figura 7. $\mathrm{O}$ jogador deve responder às perguntas do jogo até finalizar, acompanhando sua pontuação, acertos, erros e o tempo que levou jogando.

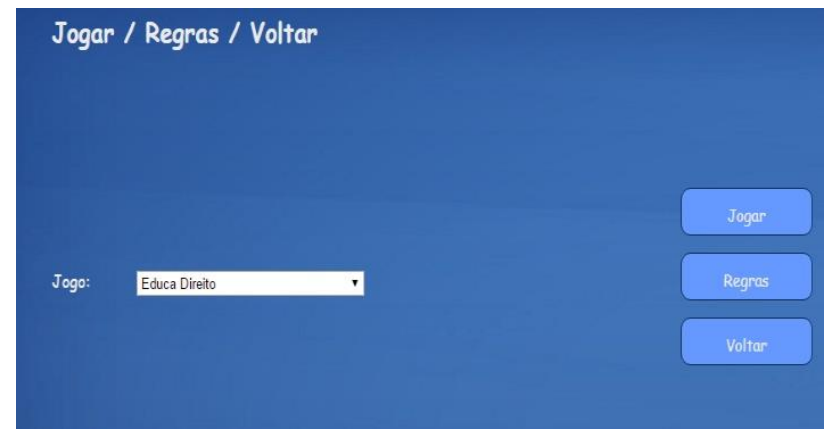

Figura 7: Tela para selecionar o jogo e escolher as opções Jogar, Regras ou Voltar

\section{Se o ator for Professor:}

- Ao se logar no jogo, deve escolher a opção de cadastrar perguntas, regras ou jogo (Figura 8), no qual vai poder jogá-lo, respondendo as questões, como foi apresentado na Figura 7.

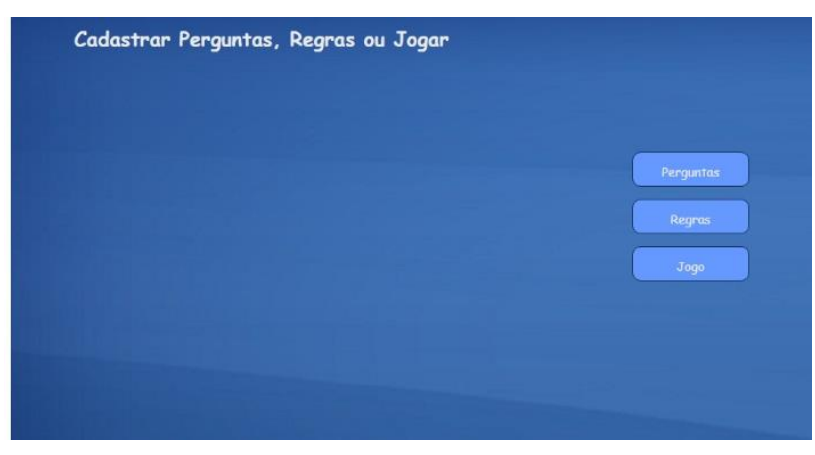

Figura 8: Tela Cadastrar Perguntas, Regras ou jogar o Jogo

Ao escolher a opção "Regras" é possível adicionar as informações que constituem as regras além de poder adicionar uma nova instituição e turma ao clicar em Novo. Na Figura 9 é possível observar a tela de cadastro de regras.

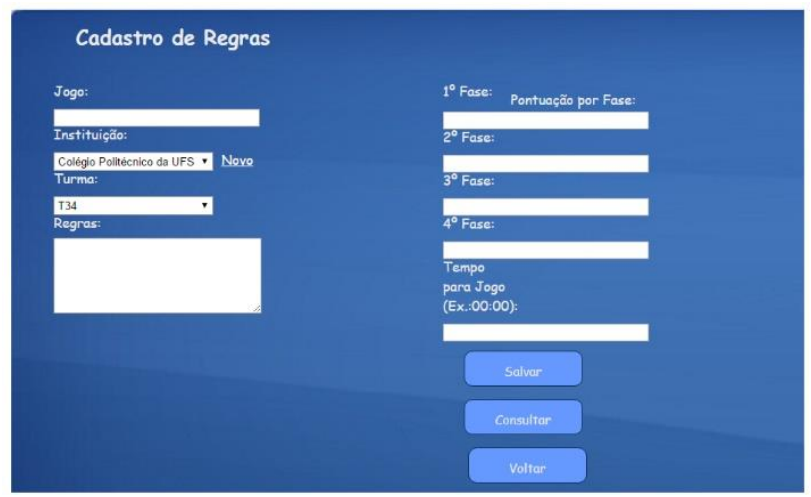

Figura 9: Cadastro de Regras

Ao clicar em Novo exibe uma nova tela com o cadastro de instituição e turma, conforme a Figura 10.

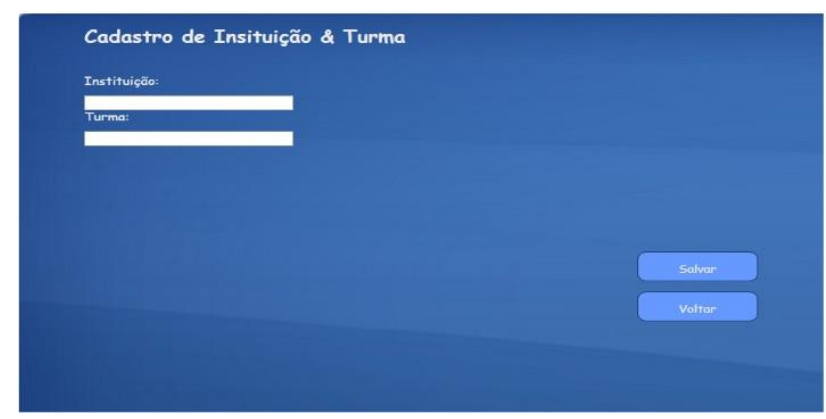

Figura 10: Tela de Cadastro de Instituição \& Turma

No cadastro de regras, existe um botão Consultar, que possibilita, consultar as informações das regras do jogo, conforme a Figura 11. A tabela de registro das regras foi desenvolvida utilizando jQuery, para facilitar a exibição das informações. 


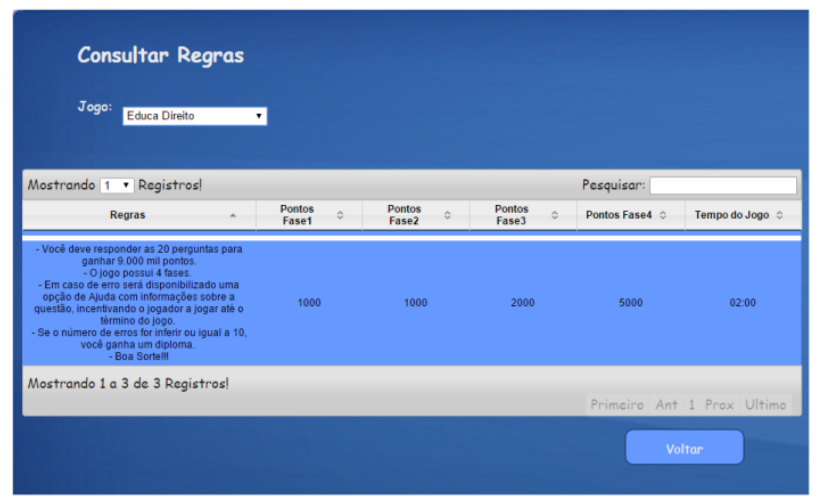

Figura 11: Tela de Consulta de Regras

Ao selecionar a opção "Perguntas" exibe uma tela para realizar o cadastro de perguntas e respostas do jogo, com dica e fases a qual a pergunta pertence, conforme a Figura 12. Também é possível consultar as questões do jogo clicando no botão Consultar, conforme a Figura 13 A tabela de registro das perguntas também foi desenvolvida utilizando jQuery.

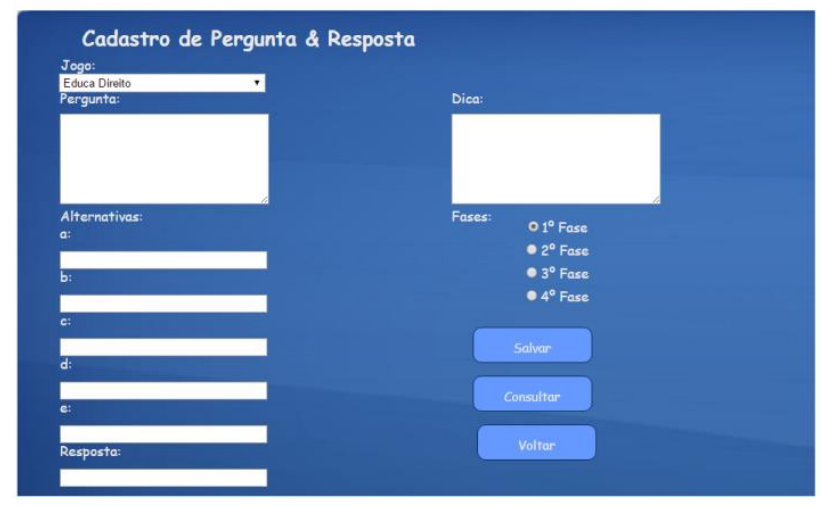

Figura 12: Tela de Cadastro de Pergunta \& Resposta

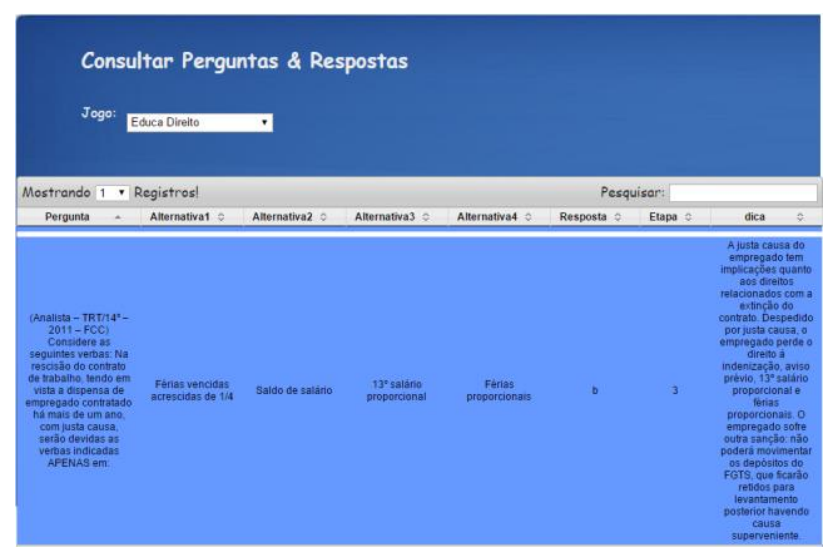

Figura 13: Tela de Consulta de Perguntas \& Respostas

O jogo em si é constituído de quatro etapas: muito fácil, fácil, média e difícil, que são compostas por cinco questões de múltipla escolha, pontuação por questão de cada fase e tempo para jogar.
O jogador deve acertar as questões e avançar de fase até finalizar e ganhar o jogo. Nas Figuras 14 e 15 é possível observar algumas questões do jogo.

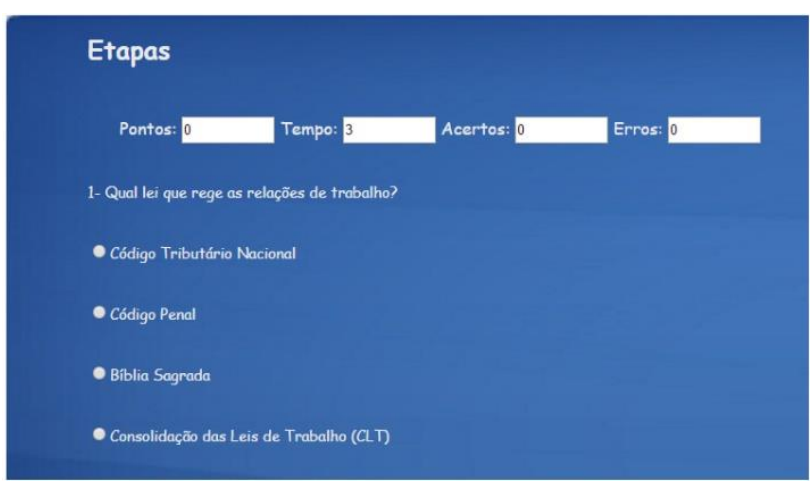

Figura 14: Tela com a pergunta 1

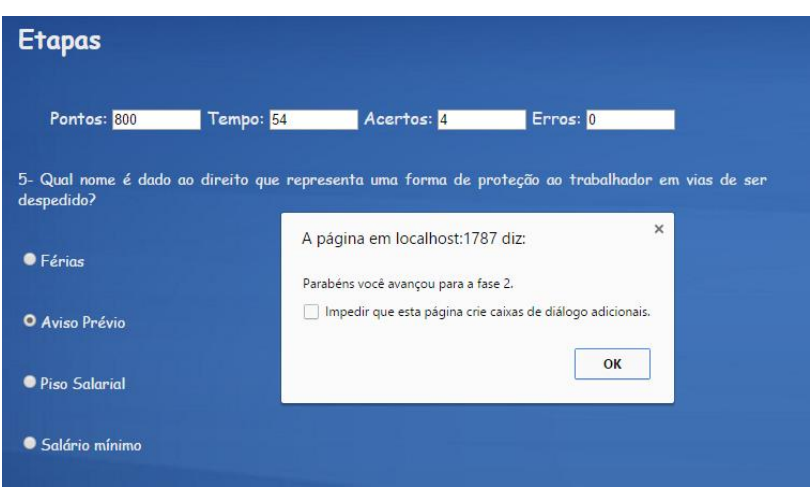

Figura 15: Tela com a pergunta 5 e a mensagem "Parabéns você avançou para fase2."

Em caso de resposta errada, conforme a Figura 16, é exibida uma mensagem informando "Resposta Incorreta" juntamente com um sinal sonoro. A questão deve ser refeita para avançar para próxima pergunta. Quando o jogador errar alguma questão, o jogo não se encerra, pois, o objetivo é incentivar ao jogador ir até o final. Também no caso de erro, o competidor vai ter a opção de dica para a questão errada, como na Figura 17. O campo Dica vai trazer novas informações referentes a questão, proporcionando um auxílio a mais sobre determinado assunto.

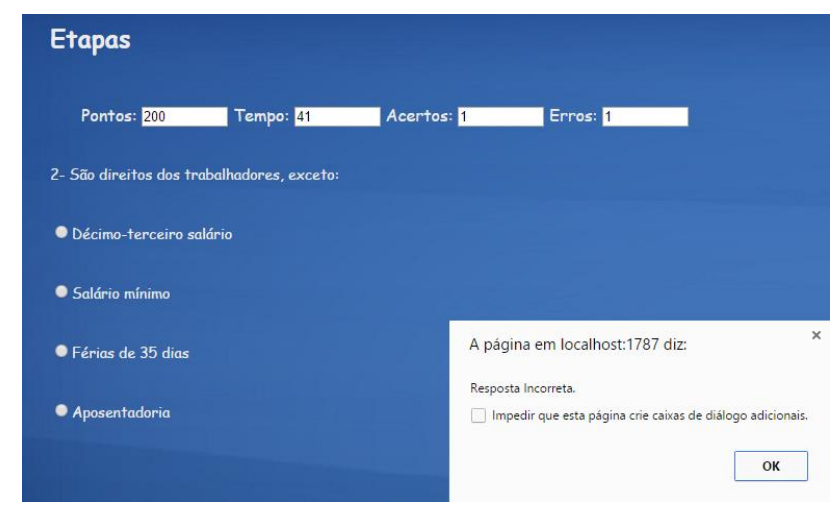

Figura 16: Mensagem "Resposta Incorreta" 


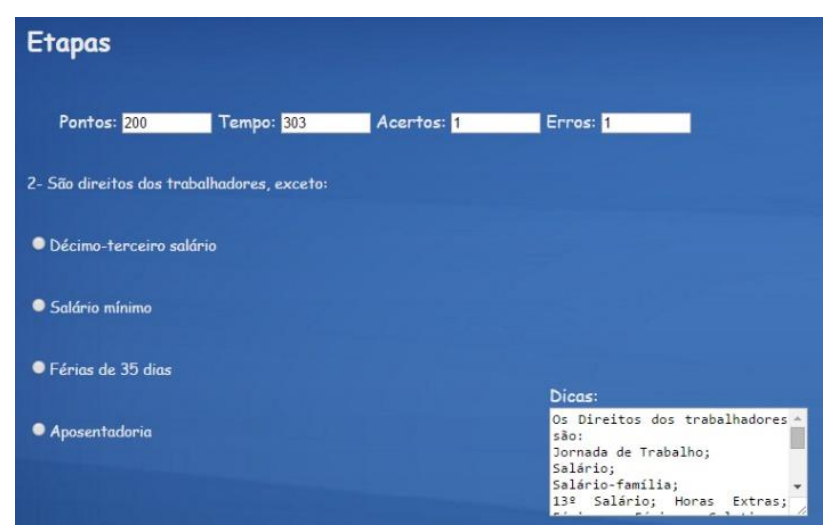

Figura 17: Exibição do campo "dica"

Em cada questão correta, é exibida uma mensagem junto com um sinal sonoro, informando que a questão está correta, conforme a Figura 18 e assim, avançando de fase até finalizar o jogo.

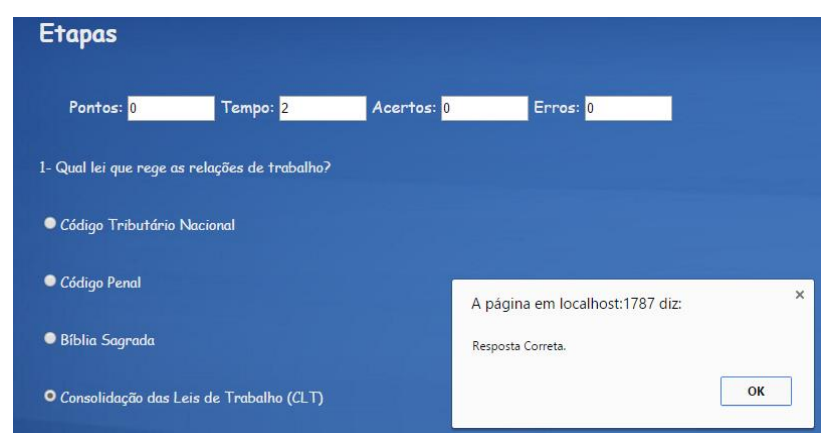

Figura 18: Mensagem "Resposta Correta"

Finalizando o jogo, será exibida a pontuação, acertos, erros e tempo - em segundos - da resolução do jogador, como na Figura 19. As perguntas devem ser respondidas até o jogador acertá-las. Assim, o total de acertos é de vinte acertos e os pontos são somados a partir dos acertos, para não diferir no final. $\mathrm{O}$ que difere é apenas o total de erros e o tempo de realização do jogo.

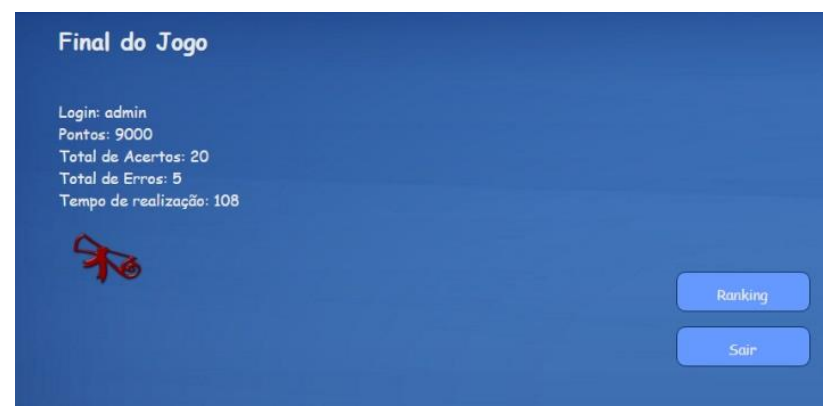

Figura 19: Tela final do Jogo

Quando o jogador alcançar o total de erros inferior ou equivalente a dez, recebe um diploma. Caso contrário, aparece uma frase "Procurar aprofundar seu conhecimento no conteúdo apresentado!"’.

Portanto, a intenção do jogo de finalizar com a pontuação do jogador é também aprender com o jogo e com os conteúdos já apresentados pelo professor em sala de aula, e não de tornar uma disputa entre os estudantes, para verificar qual é o melhor, mas sim incentivar o jogador a interpretar as questões e jogar até o final, aprofundando seu conhecimento.

\subsubsection{Avaliação e Discussão dos Resultados obtidos com o Jogo}

$\mathrm{Na}$ quinta etapa, foram aplicados dois questionários. A aplicação do primeiro questionário ocorreu para avaliar o conhecimento dos estudantes com jogos eletrônicos. O segundo questionário foi aplicado após os jogadores terem praticado o jogo, analisando o interesse dos estudantes com o mesmo. Os dois questionários foram respondidos por vinte e um estudantes, com idade entre $17 \mathrm{e}$ 22 anos, do curso técnico em Administração do Colégio Politécnico da UFSM.

Para verificar a confiabilidade dos resultados dos questionários utilizados na pesquisa, foi utilizado o método Coeficiente Alfa de Cronbach [27]. Este método mede a relação das respostas alcançadas em um questionário, através dos resultados obtidos [28].

Para [28], o Alfa de Cronbach é utilizado para estimar a confiabilidade do questionário, medindo a relação entre as respostas dos respondentes. O coeficiente alpha é calculado a partir da variância dos itens individuais e da variância da soma dos itens de cada avaliador através da equação (Figura 20) [26]. A Tabela 1 apresenta a escala de classificação do coeficiente alpha.

$$
\alpha=\left(\frac{k}{k-1}\right) \times\left(1-\frac{\sum_{i=1}^{k} s_{i}^{2}}{s_{t}^{2}}\right)
$$

Figura 20: Equação para Aplicação do Alfa de Cronbach [28]

Onde:

$\mathrm{K}$ equivale ao número de itens (perguntas) do questionário;

S2i equivale a variância de cada item;

$\mathrm{S}^{2} \mathrm{t}$ equivale a variância total do questionário, determinada como a soma de todas as variâncias.

$\mathrm{S} 2$ equivale a variância do total $\mathrm{Tj}$ de cada indivíduo $\mathrm{j}$ nos $\mathrm{k}$ itens.

\begin{tabular}{l|l}
\hline \multicolumn{1}{c|}{ Valor de Alfa } & \multicolumn{1}{c}{ Confiabilidade } \\
\hline Maior do que 0,9 & Excelente \\
\hline $0,8-\mid 0,9$ & Bom \\
\hline $0,7-\mid 0,8$ & Aceitável \\
\hline $0,6-\mid 0,7$ & Questionável \\
\hline $0,5-\mid 0,6$ & Pobre \\
\hline Menor do que 0,5 & Inaceitável
\end{tabular}

Tabela 1: Escala de classificação do Coeficiente Alfa de Cronbach [29] 
Neste sentido, foram considerados os aspectos relacionados aos interesses e conhecimentos dos estudantes com jogos eletrônicos (Tabela 2) e após a interação com a aplicação do jogo Educa Direito (Tabela 3). Com isso, para analisar os resultados obtidos com os questionários de uma maneira mais distinta, foi aplicado a Escala Likert [30] para a elaboração das alternativas. Esta escala permite medir o grau do sujeito avaliado para verificar sua concordância ou discordância com o assunto, con- forme as medidas: "concordo totalmente", "concordo parcialmente", "indiferente", "discordo parcialmente" e "discordo totalmente" [30]. Assim, os resultados alcançados foram convertidos para se adaptar a escala Likert [31], sendo que a alternativa, Discordo Totalmente equivaleu ao valor 1 , seguindo uma ordem progressiva, até a opção Concordo Totalmente, que equivaleu ao valor 5 .

\begin{tabular}{|c|c|c|c|c|c|}
\hline $\begin{array}{l}\text { 1. Você gosta de jogos eletrôni- } \\
\text { cos? }\end{array}$ & $\begin{array}{l}\text { () Concordo } \\
\text { Totalmente }\end{array}$ & $\begin{array}{l}\text { () Concordo } \\
\text { Parcialmente }\end{array}$ & ( ) Indiferente & $\begin{array}{l}\text { ( ) Discordo } \\
\text { Totalmente }\end{array}$ & $\begin{array}{l}\text { ( ) Discordo } \\
\text { Parcialmente }\end{array}$ \\
\hline $\begin{array}{l}\text { 2. Você conhece muitos jogos } \\
\text { eletrônicos? }\end{array}$ & $\begin{array}{l}\text { () Concordo } \\
\text { Totalmente }\end{array}$ & $\begin{array}{l}\text { () Concordo } \\
\text { Parcialmente }\end{array}$ & () In & $\begin{array}{l}\text { ( ) Discordo } \\
\text { Totalmente }\end{array}$ & $\begin{array}{l}\text { () Discordo } \\
\text { Parcialmente }\end{array}$ \\
\hline 3. Você joga com frequência? & $\begin{array}{l}\text { () Concordo } \\
\text { Totalmente }\end{array}$ & $\begin{array}{l}\text { () Concordo } \\
\text { Parcialmente }\end{array}$ & ( ) Indiferente & $\begin{array}{l}\text { () Discordo } \\
\text { Totalmente }\end{array}$ & $\begin{array}{l}\text { () Discordo } \\
\text { Parcialmente }\end{array}$ \\
\hline $\begin{array}{l}\text { 4. Você gosta de jogos em forma } \\
\text { de Quiz? }\end{array}$ & $\begin{array}{l}\text { ( ) Concordo } \\
\text { Totalmente }\end{array}$ & $\begin{array}{l}\text { () Concordo } \\
\text { Parcialmente }\end{array}$ & ( ) Indiferente & $\begin{array}{l}\text { ( ) Discordo } \\
\text { Totalmente }\end{array}$ & $\begin{array}{l}\text { () Discordo } \\
\text { Parcialmente }\end{array}$ \\
\hline $\begin{array}{l}\text { 5. Você usa o computador mais } \\
\text { de uma vez por dia? }\end{array}$ & $\begin{array}{l}\text { () Concordo } \\
\text { Totalmente }\end{array}$ & $\begin{array}{l}\text { () Concordo } \\
\text { Parcialmente }\end{array}$ & () Indiferente & $\begin{array}{l}\text { ( ) Discordo } \\
\text { Totalmente }\end{array}$ & $\begin{array}{l}\text { () Discordo } \\
\text { Parcialmente }\end{array}$ \\
\hline $\begin{array}{l}\text { 6. Você acessa a Internet muitas } \\
\text { vezes por dia? }\end{array}$ & $\begin{array}{l}\text { () Concordo } \\
\text { Totalmente }\end{array}$ & $\begin{array}{l}\text { () Concordo } \\
\text { Parcialmente }\end{array}$ & ( ) Indiferente & $\begin{array}{l}\text { () Discordo } \\
\text { Totalmente }\end{array}$ & $\begin{array}{l}\text { () Discordo } \\
\text { Parcialmente }\end{array}$ \\
\hline $\begin{array}{l}\text { 7. Você gosta da disciplina } \\
\text { Direito do Trabalho e Previ- } \\
\text { denciário? }\end{array}$ & $\begin{array}{l}\text { () Concordo } \\
\text { Totalmente }\end{array}$ & $\begin{array}{l}\text { () Concordo } \\
\text { Parcialmente }\end{array}$ & ( ) Indiferente & $\begin{array}{l}\text { ( ) Discordo } \\
\text { Totalmente }\end{array}$ & $\begin{array}{l}\text { () Discordo } \\
\text { Parcialmente }\end{array}$ \\
\hline
\end{tabular}

Tabela 2: Questionário Pré-Jogo

\begin{tabular}{|c|c|c|c|c|c|}
\hline $\begin{array}{l}\text { 1. Você gostou do jogo Educa } \\
\text { Direito? Achou intuitivo? }\end{array}$ & $\begin{array}{l}\text { ( ) Concordo } \\
\text { Totalmente }\end{array}$ & $\begin{array}{l}\text { () Concordo } \\
\text { Parcialmente }\end{array}$ & ( ) Indiferente & $\begin{array}{l}\text { () Discordo } \\
\text { Totalmente }\end{array}$ & $\begin{array}{l}\text { () Discordo } \\
\text { Parcialmente }\end{array}$ \\
\hline 2. Você achou o jogo difícil? & $\begin{array}{l}\text { ( ) Concordo } \\
\text { Totalmente }\end{array}$ & $\begin{array}{l}\text { () Concordo } \\
\text { Parcialmente }\end{array}$ & ( ) Indiferente & $\begin{array}{l}\text { ( ) Discordo } \\
\text { Totalmente }\end{array}$ & $\begin{array}{l}\text { ( ) Discordo } \\
\text { Parcialmente }\end{array}$ \\
\hline $\begin{array}{l}\text { 3. Você acha que o jogo estimu- } \\
\text { lou seus conhecimentos na } \\
\text { disciplina de direito do trabalho } \\
\text { e previdenciário? }\end{array}$ & $\begin{array}{l}\text { () Concordo } \\
\text { Totalmente }\end{array}$ & $\begin{array}{l}\text { () Concordo } \\
\text { Parcialmente }\end{array}$ & () Indiferente & $\begin{array}{l}\text { () Discordo } \\
\text { Totalmente }\end{array}$ & $\begin{array}{l}\text { () Discordo } \\
\text { Parcialmente }\end{array}$ \\
\hline $\begin{array}{l}\text { 4. Após o jogo, você acha que } \\
\text { passou a gostar mais de ativi- } \\
\text { dades que buscam estimular a } \\
\text { aprendizagem em sala de aula? }\end{array}$ & $\begin{array}{l}\text { () Concordo } \\
\text { Totalmente }\end{array}$ & $\begin{array}{l}\text { () Concordo } \\
\text { Parcialmente }\end{array}$ & ( ) Indiferente & $\begin{array}{l}\text { ( ) Discordo } \\
\text { Totalmente }\end{array}$ & $\begin{array}{l}\text { () Discordo } \\
\text { Parcialmente }\end{array}$ \\
\hline $\begin{array}{l}\text { 5. Você passou a ter mais inte- } \\
\text { resse por jogos sérios em sala de } \\
\text { aula, após jogar o Educa Direi- } \\
\text { to? }\end{array}$ & $\begin{array}{l}\text { () Concordo } \\
\text { Totalmente }\end{array}$ & $\begin{array}{l}\text { () Concordo } \\
\text { Parcialmente }\end{array}$ & () Indiferente & $\begin{array}{l}\text { ( ) Discordo } \\
\text { Totalmente }\end{array}$ & $\begin{array}{l}\text { () Discordo } \\
\text { Parcialmente }\end{array}$ \\
\hline $\begin{array}{l}\text { 6. Você acha que jogos sérios } \\
\text { podem vir a contribuir com a } \\
\text { aprendizagem em sala de aula? }\end{array}$ & $\begin{array}{l}\text { ( ) Concordo } \\
\text { Totalmente }\end{array}$ & $\begin{array}{l}\text { () Concordo } \\
\text { Parcialmente }\end{array}$ & ( ) Indiferente & $\begin{array}{l}\text { ( ) Discordo } \\
\text { Totalmente }\end{array}$ & $\begin{array}{l}\text { ( ) Discordo } \\
\text { Parcialmente }\end{array}$ \\
\hline $\begin{array}{l}\text { 7. Você gostaria de seguir } \\
\text { estudando, utilizando esse tipo } \\
\text { de jogo em outras disciplinas? }\end{array}$ & $\begin{array}{l}\text { ( ) Concordo } \\
\text { Totalmente }\end{array}$ & $\begin{array}{l}\text { () Concordo } \\
\text { Parcialmente }\end{array}$ & ( ) Indiferente & $\begin{array}{l}\text { ( ) Discordo } \\
\text { Totalmente }\end{array}$ & $\begin{array}{l}\text { ( ) Discordo } \\
\text { Parcialmente }\end{array}$ \\
\hline
\end{tabular}

Tabela 3: Questionário Pós-Jogo 
Nas Tabelas 2 e 3 é possível observar os valores e cálculos realizados utilizando o coeficiente Alpha de Cronbach, sendo que cada questionário foi calculado individualmente, conforme a avaliação de cada questionário.

Portanto, para garantir a confiabilidade dos resultados dos questionários aplicados com os estudantes, são confirmados a partir dos valores da Tabela 1 .

\section{Resultados}

A proposta apresentada neste estudo tem como objetivo aperfeiçoar o ensino-aprendizagem dos estudantes do curso técnico de Administração na disciplina de direito do trabalho e previdenciário, a fim de auxiliar o professor com novos métodos de ensino.

O jogo apresentado promove e estimula a construção do conhecimento do estudante, com o conteúdo apresentado pelo professor durante o semestre. Assim, o professor pode acompanhar o interesse e desempenho dos discentes com a aplicação do jogo Educa Direito.

A elaboração do jogo aconteceu a partir de um estudo relacionado a jogos educacionais ou jogos sérios para viabilizar novos meios de ensino em sala, quebrando a rotina do dia-a-dia e possibilitando que os estudantes se sintam mais estimulados a aprender o que estava sendo apresentado pelo professor. Desta forma, foi contatado o professor da disciplina para auxiliar no desenvolvimento das questões do jogo a partir dos conteúdos vistos em aula. Com isso, foi proposto, na aplicação do jogo, a possibilidade do professor se cadastrar como usuário administrador e adicionar as perguntas e regras do jogo conforme sua preferência, além de poder jogar o jogo. Já o usuário estudante vai poder visualizar as regras e jogar.
Ao finalizar, terá seu desempenho no jogo, com o total de pontos, acertos, erros e tempo.

Para avaliar o interesse dos estudantes, foram desenvolvidos dois questionários, aplicados, um antes do jogo e outro após. Com a aplicação do primeiro questionário (Tabela 3) foi possível analisar o conhecimento e interesse dos discentes em jogos eletrônicos e com o segundo questionário (Tabela 4), a possibilidade de integrar novos métodos de ensino a partir de jogos educacionais como o Educa Direito, tendo as respostas baseadas na escala Likert.

Com isso, os questionários respondidos pelos estudantes tiveram seus resultados inseridos ao coeficiente de Cronbach, como no Quadro 1 e Tabela 2.

\begin{tabular}{|c|c|c|c|c|c|c|c|c|}
\hline Questão/Usuário & Q1 & Q2 & Q3 & Q4 & Q5 & Q6 & Q7 & $\begin{array}{l}\text { Soma das } \\
\text { Respostas }\end{array}$ \\
\hline Usuário 1 & 5 & 5 & 5 & 4 & 5 & 5 & 5 & 34 \\
\hline Usuário 2 & 4 & 4 & 5 & 4 & 5 & 5 & 5 & 32 \\
\hline Usuário 3 & 4 & 4 & 5 & 4 & 5 & 4 & 5 & 31 \\
\hline Usuário 4 & 4 & 4 & 5 & 3 & 5 & 5 & 5 & 31 \\
\hline Usuário 5 & 5 & 5 & 5 & 3 & 5 & 5 & 4 & 32 \\
\hline Usuário 6 & 5 & 5 & 5 & 5 & 4 & 5 & 5 & 34 \\
\hline Usuário 7 & 5 & 5 & 5 & 5 & 5 & 4 & 5 & 34 \\
\hline Usuário 8 & 4 & 4 & 4 & 4 & 4 & 5 & 5 & 30 \\
\hline Usuário 9 & 4 & 4 & 4 & 5 & 5 & 5 & 5 & 32 \\
\hline Usuário 10 & 4 & 4 & 4 & 5 & 5 & 5 & 4 & 31 \\
\hline Usuário 11 & 3 & 3 & 3 & 3 & 4 & 5 & 4 & 25 \\
\hline Usuário 12 & 3 & 3 & 3 & 4 & 5 & 4 & 5 & 27 \\
\hline Usuário 13 & 5 & 4 & 4 & 5 & 5 & 5 & 5 & 33 \\
\hline Usuário 14 & 4 & 4 & 4 & 4 & 4 & 5 & 4 & 29 \\
\hline Usuário 15 & 4 & 4 & 5 & 4 & 5 & 5 & 4 & 31 \\
\hline Usuário 16 & 5 & 4 & 4 & 4 & 5 & 5 & 5 & 32 \\
\hline Usuário 17 & 5 & 4 & 4 & 4 & 5 & 4 & 5 & 31 \\
\hline Usuário 18 & 3 & 2 & 3 & 2 & 5 & 5 & 4 & 24 \\
\hline Usuário 19 & 4 & 5 & 4 & 4 & 5 & 5 & 5 & 32 \\
\hline Usuário 20 & 3 & 4 & 4 & 4 & 4 & 4 & 5 & 28 \\
\hline Usuário 21 & 3 & 4 & 3 & 4 & 5 & 5 & 4 & 28 \\
\hline variância & 0,56236 & 0,52154 & 0,53515 & 0,57143 & 0,18141 & \begin{tabular}{|l|}
0,18141 \\
\end{tabular} & 0,22222 & 7,3922902 \\
\hline \multicolumn{3}{|c|}{ Soma das Variầncias $\left(\mathrm{S}^{2} \mathrm{i}\right)=1,51$} & & & $\alpha=0,73$ & (Aceitável & & \\
\hline
\end{tabular}

Quadro 1: Resultado do $1^{\circ}$ Questionário

Na Figura 21 é possível observar os resultados do primeiro questionário. 


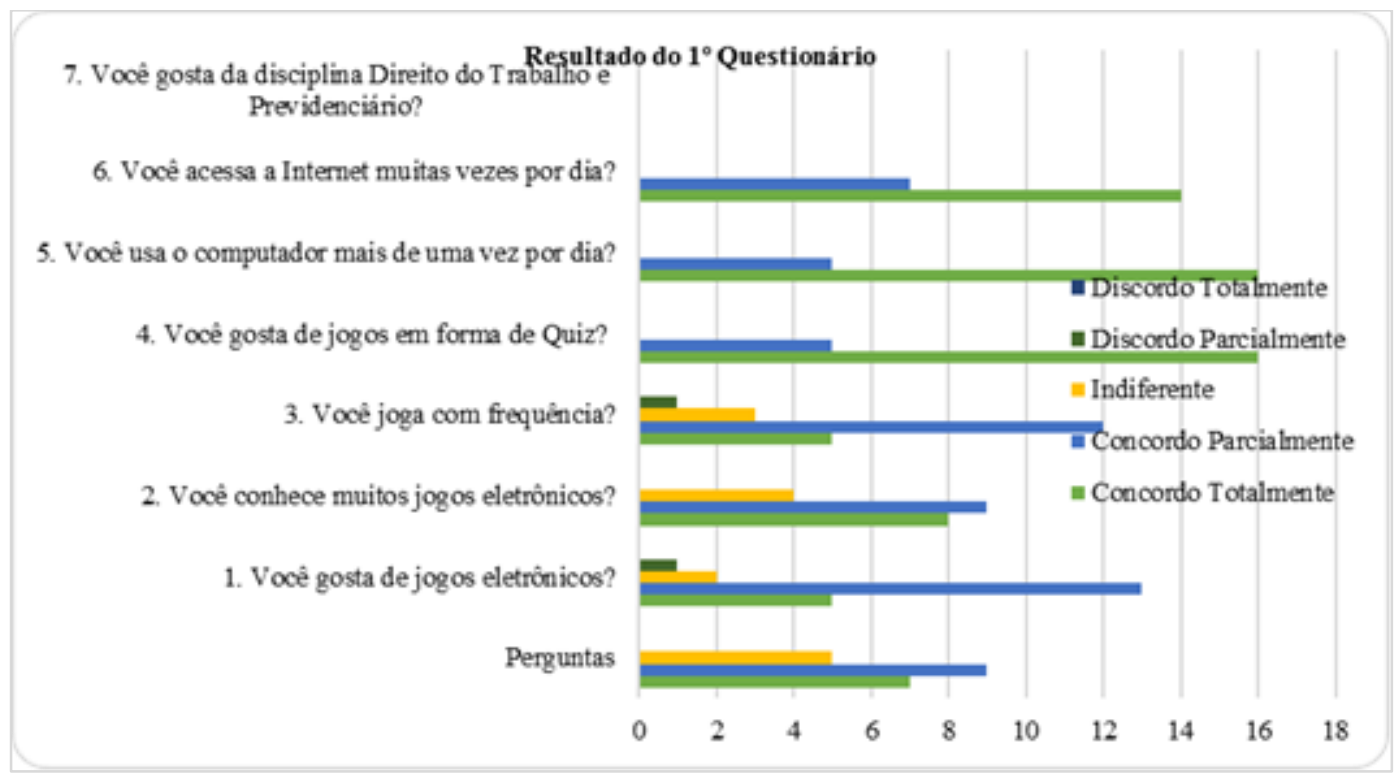

Figura 21: Resultados do $1^{\circ}$ Questionário

Os resultados obtidos com o primeiro questionário foram os seguintes:

Na primeira questão (Q1), o resultado alcançado foi positivo, pois, a maioria dos estudantes gostam de jogos eletrônicos, sendo que sete responderam "Concordo Totalmente", nove "Concordo Parcialmente" e cinco "Indiferente".

Em relação a segunda questão (Q2), foi verificado se os estudantes conhecem muitos jogos eletrônicos, sendo que cinco responderam "Concordo Totalmente", treze "Concordo Parcialmente", dois "Indiferente" e um "Discorda Parcialmente".

Com relação a terceira questão (Q3), foi observado que os estudantes jogam com frequência, sendo que oito responderam "Concordo Totalmente", nove "Concordo Parcialmente" e quatro "Indiferente".

$\mathrm{Na}$ quarta questão (Q4), verificou-se que a maioria dos estudantes gosta de jogos em formato de quiz, sendo que cinco responderam "Concordo Totalmente", doze "Concordo Parcialmente", três "Indiferente" e um "Discorda Parcialmente".

Em relação a quinta questão (Q5), notou-se que a maioria dos estudantes utiliza o computador mais de uma vez
Com relação a sexta questão (Q6), constatou-se que a maioria dos estudantes acessa a internet muitas vezes podia, sendo que dezesseis responderam "Concordo Totalmente" e cinco "Concordo Parcialmente".

$\mathrm{Na}$ sétima questão (Q7), observou-se que a maioria dos estudantes gosta da disciplina direito do trabalho e previdenciário, sendo que quatorze responderam "Concordo Totalmente" e sete "Concordo Parcialmente".

\begin{tabular}{|c|c|c|c|c|c|c|c|c|}
\hline Questão/Usuário & Q1 & Q2 & Q3 & Q4 & Q5 & Q6 & Q7 & $\begin{array}{l}\text { Soma das } \\
\text { Respostas }\end{array}$ \\
\hline Usuário 1 & 5 & 1 & 5 & 5 & 5 & 5 & 5 & 31 \\
\hline Usuário 2 & 5 & 1 & 5 & 5 & 4 & 4 & 3 & 27 \\
\hline Usuário 3 & 5 & 1 & 5 & 4 & 5 & 4 & 4 & 28 \\
\hline Usuário 4 & 5 & 1 & 5 & 5 & 5 & 5 & 5 & 31 \\
\hline Usuário 5 & 5 & 1 & 5 & 5 & 5 & 5 & 5 & 31 \\
\hline Usuário 6 & 5 & 1 & 5 & 5 & 5 & 5 & 5 & 31 \\
\hline Usuário 7 & 4 & 2 & 3 & 4 & 4 & 4 & 3 & 24 \\
\hline Usuário 8 & 4 & 1 & 4 & 4 & 4 & 4 & 4 & 25 \\
\hline Usuário 9 & 4 & 2 & 3 & 5 & 5 & 5 & 4 & 28 \\
\hline Usuário 10 & 4 & 2 & 4 & 4 & 5 & 5 & 5 & 29 \\
\hline Usuário 11 & 5 & 1 & 5 & 5 & 5 & 5 & 5 & 31 \\
\hline Usuário 12 & 5 & 1 & 4 & 4 & 4 & 4 & 4 & 26 \\
\hline Usuário 13 & 4 & 2 & 3 & 4 & 4 & 4 & 3 & 24 \\
\hline Usuário 14 & 5 & 1 & 4 & 4 & 4 & 4 & 3 & 25 \\
\hline Usuário 15 & 5 & 1 & 5 & 5 & 5 & 5 & 5 & 31 \\
\hline Usuário 16 & 4 & 1 & 4 & 4 & 4 & 4 & 3 & 24 \\
\hline Usuário 17 & 5 & 1 & 4 & 5 & 5 & 5 & 5 & 30 \\
\hline Usuário 18 & 5 & 1 & 5 & 5 & 4 & 5 & 4 & 29 \\
\hline Usuário 19 & 4 & 1 & 4 & 4 & 5 & 5 & 5 & 28 \\
\hline Usuário 20 & 5 & 1 & 4 & 5 & 5 & 5 & 5 & 30 \\
\hline Usuário 21 & 4 & 1 & 5 & 4 & 4 & 4 & 4 & 26 \\
\hline variância & 0,23583 & 0,1542 & 0,50794 & 0,24943 & 0,2449 & 0,2449 & 0,6576 & 6,61678 \\
\hline \multicolumn{5}{|c|}{ Soma das Variâncias $\left(\mathrm{S}^{2} \mathrm{i}\right)=0,40$} & & $x=0,76$ & ceitável) & \\
\hline
\end{tabular}

Quadro 2: Resultado do $2^{\circ}$ Questionário

Na Figura 22 é possível observar os resultados do segundo questionário. 


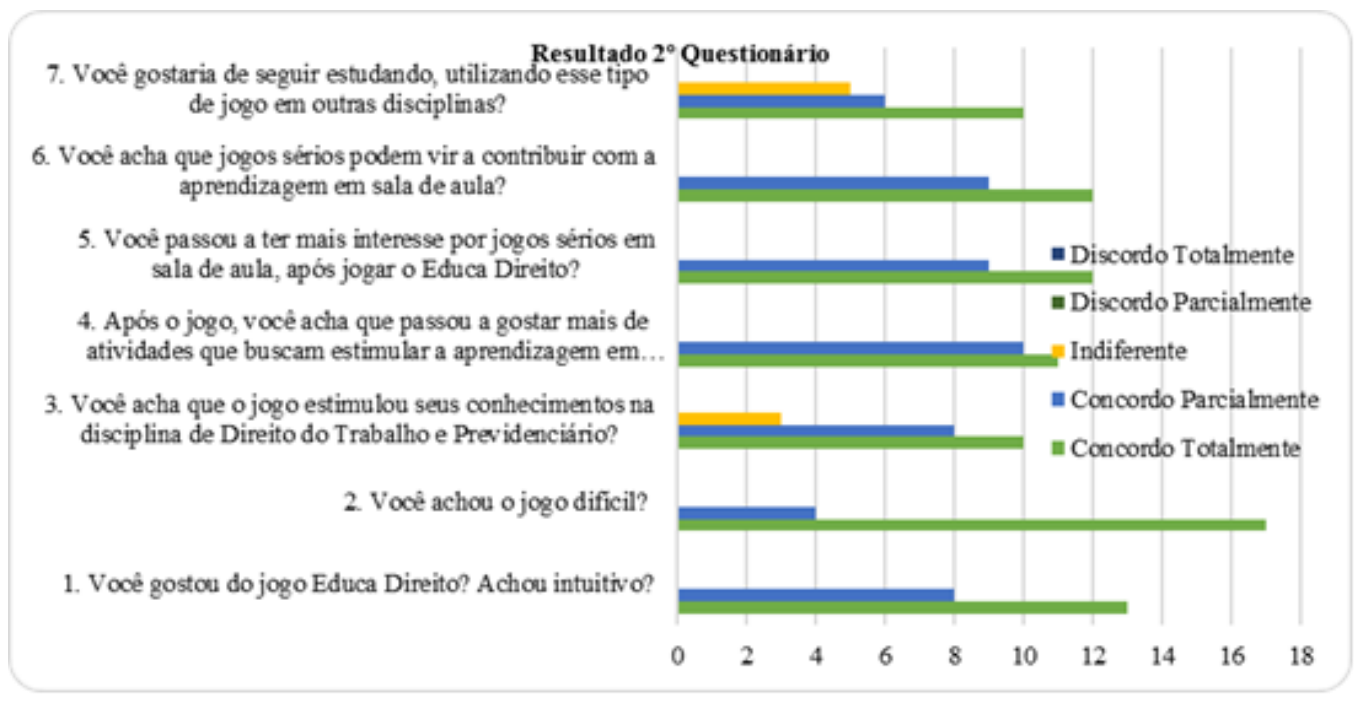

Figura 22: Resultados do $2^{\circ}$ Questionário

Os resultados obtidos com o segundo questionário foram os seguintes:

$\mathrm{Na}$ primeira questão (Q1), o resultado alcançado foi significante, pois a maioria dos estudantes gostaram do jogo Educa Direito, sendo que treze responderam "Concordo Totalmente" e oito "Concordo Parcialmente".

Em relação a segunda questão (Q2), foi perguntado aos estudantes se eles acharam o jogo difícil, sendo que dezessete responderam "Discorda Totalmente" e quatro "Discorda Parcialmente", indicando que o jogo foi fácil de jogar.

Com relação a terceira questão (Q3), foi observado que o jogo contribuiu para o conhecimento da disciplina de direito do trabalho e previdenciário, sendo que dez responderam "Concordo Totalmente", oito "Concordo Parcialmente" e três "Indiferente".

Em relação a quarta questão $(\mathrm{Q} 4)$, verificou-se que a maioria dos estudantes passou a gostar mais de atividades que buscam estimular a aprendizagem em sala de aula, sendo que onze responderam "Concordo Totalmente" e dez "Concordo Parcialmente".

$\mathrm{Na}$ quinta questão (Q5), notou-se que a maioria dos estudantes passou a ter mais interesse por jogos sérios em sala de aula, após jogar o Educa Direito, sendo que doze responderam "Concordo Totalmente" e nove "Concordo Parcialmente".

Com relação a sexta questão (Q6), constatou-se que a maioria dos estudantes acham que jogos sérios podem vir a contribuir com a aprendizagem em sala de aula, sendo que doze responderam "Concordo Totalmente" e nove "Concordo Parcialmente".

Em relação a sétima questão (Q7), observou-se que a maioria dos estudantes gostaria de seguir estudando, utilizando esse tipo de jogo em outras disciplinas, sendo que dez responderam "Concordo Totalmente", seis "Concordo Parcialmente" e cinco "Indiferente".

Com a aplicação do jogo Educa Direito percebeu-se que jogos sérios estão sendo cada dia mais trabalhados em sala de aula, com o objetivo de integrar novos recursos de aprendizagem aos estudantes, para desta forma auxiliar em sua aprendizagem, abrangendo o estilo de aprendizagem de cada estudante. Assim, percebeu-se sua aceitação pelos estudantes, pois é uma maneira diferente da rotina da sala de aula que possibilita a aprendizagem através de jogos educacionais.

\section{Conclusões}

A aprendizagem faz com que o estudante construa novos conhecimentos a partir do é aprendido e vivenciado no seu dia-a-dia, na escola, em casa, na rua, em todo lugar e com isso, faz com que o professor procure desenvolver novos métodos, situações que estimulem o raciocínio dos estudantes em sala de aula [4]. Neste sentido, os jogos sérios estão crescendo e se expandindo para buscar enriquecer a aprendizagem dos estudantes, frente ao conhecimento

sta forma, o objetivo deste trabalho é desenvolver um jogo sério web para o ensino da disciplina de direito do trabalho e previdenciário do curso Técnico em Administração do Colégio Politécnico da UFSM para melhorar o processo de ensino-aprendizagem dos estudantes.

Portanto, o propósito do jogo Web é facilitar o ensino realizado pelo professor, com novas ferramentas que permitem a integração dos conteúdos com novos meios de interação ao estudante. 
Com os resultados das avaliações, foi possível perceber que novos meios de ensino podem auxiliar na aprendizagem dos estudantes, devido à diversidade que cada estudante tem em aprender o conteúdo que é apresentado pelo professor.

Como trabalhos futuros, propõem-se uma opção para o professor alterar o layout da página conforme o tema do jogo, também a possibilidade de adaptá-lo para dispositivos móveis como, smartphones, tablets, criar jogos para outras disciplinas, além de alterar o jogo para quando o jogador errar a questão, avançar para próxima questão para no final exibir o ranking com a posição do usuário. Outra opção seria outros tipos de questões como verdadeiro ou falso, múltipla escolha com respostas múltiplas e descritiva.

\section{Referências}

[1] A. A. M. Rolim; S. S. F. Guerra; M. M. Tassigny. Uma leitura de Vygotsky sobre o brincar na aprendizagem e no desenvolvimento infantil. Rev. Humanidades, Fortaleza, v. 23, n. 2, p. 176-180, 2008.

[2] M. K. Oliveira. Vygotsky: Aprendizado e desenvolvimento: um processo sócio-histórico. Scipione, $5^{\mathrm{a}}$ ed., São Paulo, p. 58-81, 2010.

[3] C. P. Grosso. Limites da Flexibilização no Direito do Trabalho à Luz do Desenvolvimento Econômico e Social. Dissertação Mestrado. Programa de Mestrado em Direito da Universidade de Marília. Marilia, SP, 2007.

[4] M. S. Soares. Projeto de Jogos Educativos 2D de Aventura usando Lua. Dissertação de Mestrado. Programa de Pós-graduação em Informática do Centro técnico Cientifico da PUC - Rio. Rio de Janeiro, RJ, 2012.

[5] V. C. Pádua. Ambiente de suporte a jogos WEB voltado para a área de ensino a distância. Dissertação de Mestrado. Pós-graduação em Ciência da Computação do Centro de Informática da Universidade Federal de Pernambuco. Pernambuco, Recife, 2008.

[6] R. Medeiros; R. Lima; D. Silva; L. Mercado. Jogos Digitais como Estratégia de Ensino-Aprendizagem no Ensino Superior: a construção e aplicação do game Renascença na disciplina de Literatura. Anais do Seminário de Jogos Eletrônicos, Educação e Comunicação, v. 1, n. 1, 2015.

[7] L. P. L. Mercado. Metodologias de Ensino com Tecnologias da Informação e Comunicação no Ensino Jurídico. Avaliação: Revista da Avaliação da
Educação Superior, v. 21, n. 1, 2015.

[8] T. G. Silva. Jogos Sérios em Mundos Virtuais: Uma Abordagem Para o Ensino-Aprendizagem de Teste de Software. Dissertação de Mestrado. Pósgraduação em Informática, Área de Concentração em Computação Aplicada da Universidade Federal de Santa Maria - UFSM. Santa Maria, RS, 2012.

[9] M. Zyda. From Visual Simulation to Virtual Reality to Games. IEEE Computer Society, http://ieeexplore.ieee.org/xpls/icp.jsp?arnumber=151 0565, Set. 2015.

[10] G. Tolentino; L. S. Oliveira; A. Ventura; A. B. Matida; C. Battaglini; R. J. Oliveira. Usabilidade de jogos virtuais e frequência cardíaca de usuários. Um estudo comparativo. In: VIII Brazilian Symposium on Games and Digital Entertainment. Rio de Janeiro, RJ, p. 117-120, 2009.

[11] M. Kebritchi; A. Hirumi. Examining the pedagogical foundations of modern educational computer games. Computers \& Education, v. 51, n. 4, p.1729-1743, 2008.

[12] G. Pretti. História e Princípios do Direito do Trabalho. Clube de Autores. 53 p., 2012.

[13] F. G. Villela. Manual do Direito: Teoria e Questões. Elsevier. ISBN: 978-85-352-3874-7, 504 p., 2010.

[14] S. P. Martins. Direito do trabalho. Atlas, $25^{\mathrm{a}}$ ed., São Paulo, 876 p., 2009.

[15] R. G. Schwarz. Direito do trabalho. Campus. ISBN: 978-85-3522-460-3. 235 p., 2007.

[16] L. C. Robortella. O Moderno Direito no Trabalho. Editora LTr, São Paulo, 336 p., 1994.

[17] A. M. Nascimento. Curso de Direito do Trabalho. Saraiva, 11 a ed., São Paulo, 738 p., 1995.

[18] M. I. M. S. A. Cunha. Direito do Trabalho. Saraiva, $3^{\mathrm{a}}$ ed., São Paulo, 261 p., 2004.

[19] V. V. S. Carvalho; C. H. R. Gonçalves; J. C. Soares; F. M. Barreto; J. M. Soares; G. Barroso. Criação de Jogos Didáticos de Perguntas e Respostas por meio de Modelagem em Redes de Petri Coloridas Hierárquicas; In. XXV Simpósio Brasileiro de Informática na Educação, p. 352-356, 2014.

[20] T. S. C. Silva; J. C. B. Melo. Cidade dos Bits: Um game para auxiliar no Aprendizado dos Fundamentos da Ciência da Computação a Nível Médio. In: II Congresso Brasileiro de Informática na Educação XXIV Simpósio Brasileiro de Informática na Educação, p. 915-919, 2013. 
[21] R. Russell. The Job Jungle: A Labor Market Game. http://www.fte.org/teacher-resources/lessonplans/efllessons/the-job-jungle-a-labor-market-game

[22] A. C. GIL. Como Elaborar Projetos de Pesquisa. Atlas, 5 ed., São Paulo, 202 p., 2010.

[23] R. S. Wazlawick. Metodologia de Pesquisa para Ciência da Computação. Elsevier. ISBN (versão eletrônica): 978-85-352-6643-6, 137 p., 2009.

[24] Microsoft. Introdução à linguagem $\mathrm{C \#}$ e ao .NET Framework. https://msdn.microsoft.com/ptbr/library/z1zx9t92.aspx, Set. 2015.

[25] jQuery. jQuery Write less, do more. https://jquery.com/, Dez. 2015.

[26] C. Cabral; W. Caprino. Trilhas em Segurança da Informação: Caminhos e ideias para a proteção de dados. Brasport Livros e Multimídia Ltda, Rio de Janeiro, 242 p., 2015.

[27] L. J. Cronbach. Coefficient Alpha and The Internal Structure of Tests. Psychometrika, v.16, n.3, p.297334, 1951.

[28] H. R. M. Hora; G. T. R. Monteiro; J. Arica. Confiabilidade em Questionários para Qualidade: Um Estudo com o Coeficiente Alfa de Cronbach. Produto \& Produção, vol. 11, n. 2, p. 85 - 103, 2010.

[29] D. George; P. Mallery. SPSS for Windows Step by Step: A Simple Guide and Reference Fourth Edition (11.0 update). Boston: Allyn e Bacon, [S.1.], $4^{\mathrm{a}}$ ed. v.12, n.12, p.63, 2003.

[30] L. M. A. Cunha. Modelos Rasch e Escalas de Likert e Thurstone na medição de atitudes. Dissertação Mestrado em Probabilidades e Estatística. Universidade de Lisboa, Faculdade De Ciências, Departamento de Estatística e Investigação Operacional. 2007.

[31] R. Likert. A Technique For The Measurement Of Attitudes. Archives of Psychology, [S.1.], v.22, n.140, p.1-55, 1932. 